\title{
Therapy of Gastroesophageal Reflux: Evidence-Based Approach to Antireflux Surgery
}

\author{
Lars Lundell \\ Department of Surgery, Karolinska University Hospital, Huddinge, Stockholm, Sweden
}

\section{Key Words}

Gastroesophageal reflux disease • Medical therapy •

Antireflux surgery · Proton pump inhibition •

Postfundoplication symptoms · Laparoscopy

\begin{abstract}
Background: Due to the chronic, relapsing nature of gastroesophageal reflux disease, lifelong therapeutic options have to be considered and recommended in many patients. Accordingly, surgical repair has to be evaluated based on modern, evidence-based methodologies. Methods: A careful review has been carried out of the relevant surgical literature also including trials incorporating direct comparisons between medical and surgical therapies. The outcome of such a survey has been structured according to the grading of evidence from highest grade I to the lowest III. Results: Grade I evidence exists to show that antireflux surgery is more effective than proton pump inhibition in the control of reflux-related symptoms. Side effects are burdening surgical repair, many of which do not decrease over time. Data are not consistent to show any benefit of surgery whenever health economic outcomes are required. Minor differences are in favor of laparoscopic operations and it does matter who is doing the operation and how the repair is completed. Better data are requested to assess the true long-term effi-
\end{abstract}

cacy (>10 years) of corresponding operations. Conclusion: Antireflux surgery is an effective and durable therapeutic modality in the long-term management of gastroesophageal reflux disease.

Copyright $\odot 2007$ S. Karger AG, Basel

The predominance and the frequently chronic nature of gastroesophageal reflux disease (GERD) expose the clinician to the key question of which therapeutic strategy should be chosen in each individual patient. No doubt, modern medical therapy has documented its efficacy and attractiveness in the short-term perspective. This is true both for those GERD patients who present with erosive as well as non-erosive disease. When this therapeutic concept of selective acid secretory inhibition is translated into the long-term management perspective, the following conclusions regarding proton pump inhibition (PPI) seem to be justified [1-13]:

- Most trials evaluating the efficacy of PPIs have a trial design, including duration of therapy, not extending beyond 6 months.

- Around $65-90 \%$ of the patients are kept in clinical remission depending on the presence of esophagitis at baseline and the severity of the esophagitis as assessed by the Los Angeles system.

\section{KARGER}

Fax +4161306 1234 E-Mail karger@karger.ch www.karger.com
(C) 2007 S. Karger AG, Basel

0257-2753/07/0253-0188\$23.50/0

Accessible online at:

www.karger.com/ddi
Lars Lundell

Department of Surgery, Karolinska University Hospital

SE-141 86 Stockholm (Sweden)

E-Mail lars.lundell@karolinska.se 
- There exists a rough association between the capacity of PPIs to inhibit the parietal cells and the subsequent short- and long-term efficacy of that therapy. Consequently, the S-enantiomer of omeprazole has been found to be more effective than the first generation of PPIs.

- Patients with Barrett's esophagus appear to be more resistant to medical therapy, within the corresponding therapeutic time frames, with esophagitis healing rates in the same range as reported in Los Angeles grade C and $\mathrm{D}$ cases. Based on the pathogenetic role of duodenal-alkaline juice components for the eventual occurrence and further development of columnar metaplasia of the esophagus, it can easily be recognized that PPI therapy has its limitations in these patients.

- There is a relationship between the amount of acid refluxed into the esophagus and the grading of the esophagitis according to the Los Angeles system also related to the presence or absence of complications to GERD (such as Barrett's esophagus).

The question which needs to be answered is, however, whether the therapeutic ceiling is now reached, above which the acid inhibition concept cannot pass? Indeed it has to be mentioned that PPI therapy has effects also on the reflux of duodenal juice components into the esophagus. Whether this is relevant for the interference with basic pathogenetic mechanisms in for example the columnar metaplastic epithelium is as yet unknown. Based on corresponding background considerations, the clinician frequently asks the question which therapeutic strategy should be recommended in GERD patients suffering from a chronic disease eventually requiring lifelong administration. Furthermore, there will be other factors that need to be incorporated into the decision-making process such as respiratory complication to reflux, incomplete response to PPI and the willingness of the patient to continue PPI therapy for his/her remaining lifetime. Ultimately this leads to the question of whether surgical therapy can be a therapeutic option in similar GERD patients and how the prospects are and will be for a longterm successful outcome. This review covers the evidence (grade I and II level of evidence) which can guide the clinician in the decision-making process relevant to the following questions (table 1): (1) How effective is antireflux surgery (ARS) compared to modern medical therapy in the long-term management of GERD? (2) What is the evidence supporting one operative approach from the other? (3) If the ARS strategy is endorsed, how should this surgery be done to maximize GERD control and minimize side effects?

Evidence-Based Surgery
Table 1. Classification of the level of evidence for propositions

Evidence obtained from at least one properly randomized, controlled trial

IIa Evidence obtained from well-designed, controlled trials without randomization

IIb Evidence obtained from well-designed, cohort or casecontrol analytical studies, preferably from more than one center or research group

IIc Evidence obtained from comparisons between times or places with or without intervention, or dramatic results in uncontrolled experiments

III Opinions of respected authorities, based on clinical experience, descriptive studies or reports of expert committees

\section{Medical versus Surgical Therapy}

Before the late 1990s, grade I evidence strongly favored the superiority of ARS over medical therapy. There are, however, two major problems burdening these studies. First of all the medical comparator used is now totally outdated and second transthoracic surgical approaches are currently only exceptionally practiced [14-16]. With the advent of PPI therapy, the obvious question arose whether a therapeutic option could compete with ARS in terms of efficacy? This was a most pertinent question to be formulated since a comprehensive comparison should incorporate aspects on both safety, practicalities confined to the therapy and side effects.

With the passage of time, grade I evidence has emerged. These studies can basically be divided into two different categories. One is exemplified by the long-term follow-up of the US veteran study [17]. Hereby an agency was recruited to search each individual 10 years after the randomization and thereby complete the follow-up. This follow-up was apparently launched at a timepoint not predefined in the original protocol. Consequently, only a limited number of patients allocated to ARS were found and therefore the general applicability of these results is highly questionable. The methodological pitfalls are obvious when a study population becomes too diluted with an apparent risk for both type I and type II errors. One such example is the survival advantages in those US veterans assigned to medical therapy (mostly PPI therapy), a finding which does not make sense from either more general perspectives or from the viewpoint that prospective, controlled data have not demonstrated a similar det-

Dig Dis 2007;25:188-196 
rimental effect of ARS [18, 19]. Anyhow, data emerging from that former long-term follow-up of patients randomized to ARS raised significant concern regarding the durability of the reflux control to which operation-specific side effects could also be added.

The second study, representing grade I evidence, is represented by the Nordic multicenter trial comparing open ARS with varying doses of omeprazole $[18,19]$. This study has now completed its 7-year follow-up. Moreover, UK-based trials recently presented the short- and longterm follow-up of a cohort of selected GERD patients allocated either to laparoscopic Nissen (total) fundoplication or PPI therapy [20,21]. These studies have a common denominator in that ARS is superior to PPI when it comes to reflux control. The outcome variables used in the different studies are, however, very different, which may explain why there seemed to be more obvious differences in favor of ARS in the UK trials.

When comparing fundamentally different therapeutic strategies such as medical and surgical therapy, it is of vital importance to recognize the complexity in capturing data that allows a relevant comparison between respective strategies. It can be argued that a composite score may offer obvious advantages before focusing on one or more disease-specific symptoms. In the Nordic trial a composite score predefined as 'treatment failure' was applied, whereupon the accumulation of those over time was analyzed by use of survival statistics. The complexity confined to a similar comparison is also exemplified by the use of quality-of-life instruments [22-25]. These can be of either disease-specific or of generic type. The latter revealed quite minor differences between omeprazole and open ARS, whereas the disease-specific or Gastrointestinal Symptom Rating Scale showed difference in favor of ARS in reflux dimensions, whereas the postfundoplication side effects expressed themselves in other gastrointestinal dimensions within the same instrument. Although it can be concluded that ARS can very effectively compete with modern medical therapies, it is a key issue how to minimize the side effects to fully recognize and more widely recommend it for selected patients.

\section{Selection of Patients for ARS}

Although ARS can only be a therapeutic alternative in a minority of patients suffering from chronic GERD, the issue of selecting the right patient is critical. Traditionally, only patients with erosive GERD have been considered candidates for ARS. In fact, most random- ized controlled trials within this research area have exclusively enrolled such patients. During the last decade it has, however, become apparent that at least half of GERD patients who present with significant intensity, frequency and duration of typical reflux symptoms do not have mucosal breaks of the time of diagnostic endoscopy. It is even questionable whether such individuals will ever develop erosive disease. In the early periods of ARS development, many researchers questioned whether patients with non-erosive GERD, in whom daytime acid reflux predominated, were good candidates for ARS [26-32]. With the passage of time, solid grade II evidence has accumulated showing that there are no obvious differences in the success rates between erosive and non-erosive GERD when submitted to ARS. The key importance of carrying out ambulatory 24-hour $\mathrm{pH}$ monitoring in this group of patients cannot be overemphasized before embarking on surgical therapy. Recently another problematic group of patients with alleged GERD has come into focus. When patients, who are either poor-partial responders to PPI and even designated as non-responders, are submitted to advanced investigations including combined impedance, acid and bile reflux detection, intriguing findings have been reported [33]. Some of these patients apparently present with mixed reflux, mild acid reflux to pure alkaline reflux. To this, a high symptom association probability can be added. Challenging pilot data have been presented to show that the response to ARS may be most favorable even in these very difficult cases. At this stage the level of evidence for the role of surgery in these situations can only be classified as grade $\mathrm{C}$, but future research will further clarify the picture.

It has been notoriously difficult to define the role of ARS in patients with proposed respiratory complications of GERD. It is most probable that the use of the same advanced, combined technologies, as described above, may sharpen our tools to significantly better select those patients who may benefit from a 'complete' control of reflux as accomplished by an antireflux repair. Until now we have to conclude that the level of evidence is at the best only grade $\mathrm{B}$, but more likely approaching grade IIc when it comes to the efficiency of ARS by which such an operation deals with eventual respiratory complications to GERD. This is also true for chronic cough, posterior laryngitis, hoarseness as well as straightforward asthma and chronic bronchitis [34, 35].

The other extreme and complicated manifestation of GERD is represented by peptic strictures and Barrett's esophagus. Referring to the former, a number of single 


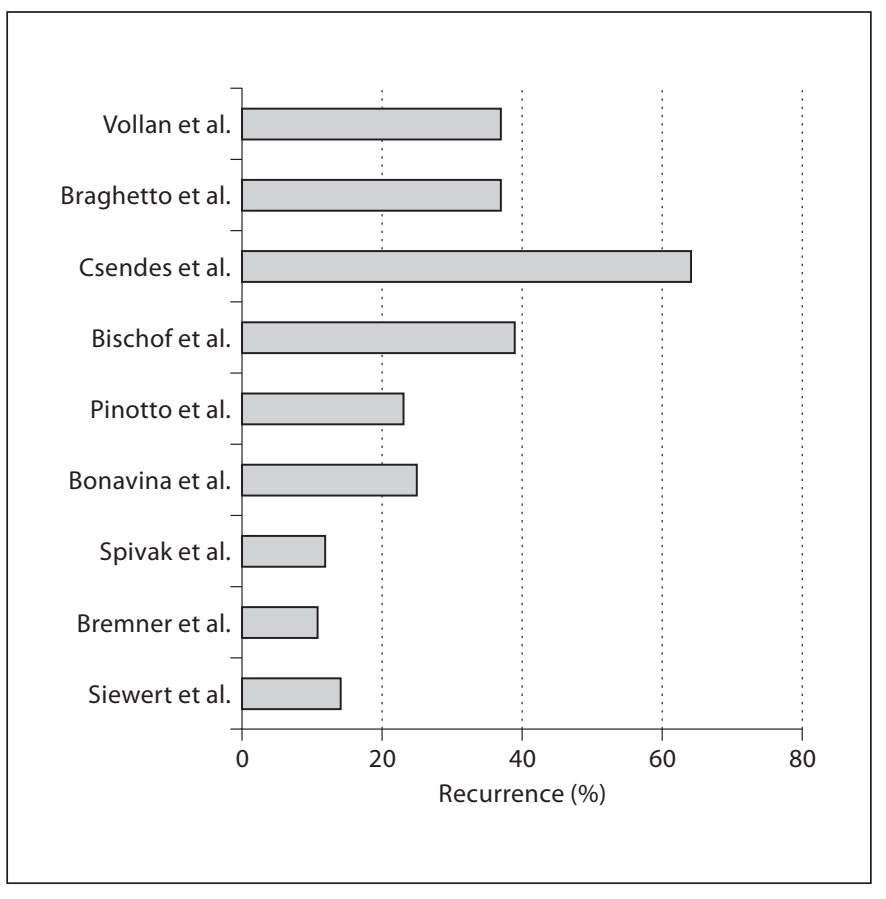

Fig. 1. Review of outcomes reported in the literature covering conservative surgical treatment of GERD patients with peptic strictures.

institution series have been presented to which can be added a fair amount of case series [36-44]. Therefore, the level of evidence supporting the efficacy of ARS in combination with endoscopic dilatation can only reach grade IIc (fig. 1).

Barrett's esophagus presents many challenges for the surgeon. Traditionally this condition has been looked upon as a robust and frequently practiced indication for ARS. In fact, two randomized trials have been published to show the superiority of ARS over medical therapy, studies which have incorporated follow-up periods in the range of 5 years $[15,45]$. This grade I evidence (with some limitation due to the restricted number of patients enrolled) demonstrates the superiority of ARS both in terms of histomorphological evaluation of the metaplastic epithelium as well as in terms of conventional clinical outcome variables. When it comes to the long-term outcome of ARS in Barrett's cases, the level of evidence is reduced to grade IIb and IIc, depending on the suboptimal study designs and inconsistencies in data capturing. No doubt some researchers have reported quite dismal results by laparoscopic Nissen fundoplication advocating even transthoracic operative approaches in selected cases. Moreover, even mutilating procedures such as vagotomy

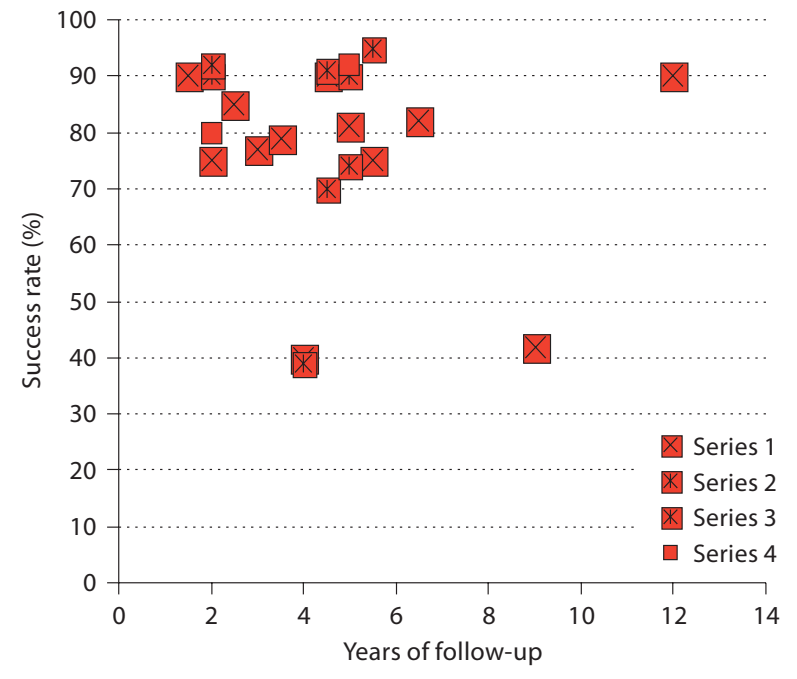

Fig. 2. Literature review of the level of success after ARS in Barrett's patients.

gastric resection with biliary diversion have been proposed. When collecting data from the literature [46-64], which can be classified as belonging to category I-IIc, a picture emerges that reveals quite favorable and reassuring long-term results of conventional antireflux repair in patients with Barrett's esophagus (fig. 2)

\section{Laparoscopic or Open Approach to ARS?}

This topic has comprehensively been tackled in a recent meta-analysis by Catarci et al. [65]. Despite a quite impressive number of studies, carried out during the last decade, it became evident that significant scientific flaws burdened most study protocols [66-75]. This is illustrated by the lack of blinding in all but two protocols, profound underpowering and suboptimal level of experience regarding the laparascopic technique. Bearing these drawbacks in mind it seems as if the following conclusions can be drawn: (1) The short and medium long-term results seem to be in the same range after laparoscopy compared to open antireflux repair. (2) The immediate postoperative course is smoother after laparoscopy and the hospital stay somewhat shorter. (3) Health economic analyses are 
few and incomplete, but significant advantages in favor of the laparoscopic strategy cannot be demonstrated due to longer operating time, expensive equipment and no clearcut reduction in indirect costs driven by shorter sick leave during the postoperative recovery period.

With this information as a background and the fact that laparoscopy, as a surgical technique, has been accepted by and disseminated throughout the surgical community as well as among patients, it seems as if the question whether ARS should be carried out by minimal invasive technologies or not belongs to the category 'nonissue'.

\section{Whose Fundoplication and Why?}

No doubt, a total fundoplication, either modified from or constructed according to the principles originally outlined by Nissen, is the most frequently performed antireflux operation worldwide [1-3, 76]. This surgical approach to the long-term control of GERD has even further been popularized by the introduction of laparoscopy. The well-known downside of a total fundoplication is the mechanical side effects which seem to occur as a consequence of an overcorrection of the antireflux barrier in the gastroesophageal junction area. This results in some degree of dysphagia, inability to belch, postprandial bloating and flatulence [77-81]. These issues are of crucial importance, particularly in a clinical situation where effective medical therapeutic alternatives are available and harbor documented efficacy. To circumvent at least some of these drawbacks with the total fundoplications, various forms of partial fundoplications have been launched and further explored to further ascertain their efficacy and mode of action [82-85]. In order to understand the eventual role of fundoplications in the surgical treatment of GERD, one has to understand the essentials of pathogenetic mechanisms into which fundoplication operations interact. Furthermore, the mechanisms which cause postfundoplication complaints have to be clarified and the degree by which partial or total fundoplications interfere with those relevant to the occurrence of postoperative complaints.

The effects of partial versus total fundoplications have been investigated in 9 randomized clinical trials. Six were open laparotomy operations and 3 trials used laparoscopic approach. The studies were published from 1974 to 2002 . To these are also added some single-institution, prospective but uncontrolled observations [65, $86-95]$. Concerning the partial fundoplications, the pos- terior partial type of operation was evaluated in 5 of these trials, the Hill repair in 2, and the Lind subtotal posterior wrap in 1 , and the anterior fundoplication in 1 study. The scheduled postoperative follow-up period ranged from 4 months to 8 years. No significant differences were found between partial versus total fundoplications in terms of new onset dysphagia and recurrence of gastroesophageal reflux symptoms. Re-operations for failure were carried out in $1.5 \%$ of those having a partial fundoplication compared to $9.6 \%$ of those having a total fundoplication, a difference which was considered to be significant [65]. In the largest randomized trial comparing a posterior with a total fundoplication, which covered more than 10 years of follow-up, both procedures displayed the same level of reflux control. Based on the reassuring long-term follow-up data, it is difficult to understand why some investigators have found Toupét fundoplication not to be as successful as a total fundoplication, in severe cases of reflux disease particularly when performed by means of a laparoscopy. It cannot be denied, of course, that some procedures are more difficult to perform when modern minimal invasive techniques are applied. In a search for factors that may have affected the outcome after the respective procedures, it has been difficult to demonstrate that the severity, the duration of disease, hiatal closure by crural repair or body mass index had any impact on the level of long-term reflux control.

Survey of the controlled, clinical trial literature concerning posterior partial fundoplication shows that the level of clinical reflux control is not entirely similar to what can be reached by a total wrap, when studied by ambulatory 24-hour $\mathrm{pH}$ monitoring. After the former procedure it is evident that the esophageal acid exposure is reduced to near zero values. This contrasts to observations made in patients having a partial wrap where corresponding values are in the ranges considered to be normal.

\section{Are All Partial Fundoplications Followed by the Same Results?}

Since prevention is the best strategy, not the least since we lack effective treatment of established severe postfundoplication symptoms, it is important to raise the question whether all partial fundoplications are followed but the same results? It seems beyond any doubt that fewer troubles and complaints of rectal flatulence follows a partial fundoplication compared to a total wrap [96- 
102]. In a recent randomized clinical trial the question was addressed whether there are important differences between an anterior and a posterior partial fundoplication in terms of reflux control and side effects [103]. This trial incorporated almost 100 patients with a limited follow-up. Despite these drawbacks, significant differences were noted in favor of the posterior fundoplication regarding the level of reflux control. Even when only daytime acid exposure was objectively assessed, the outcome after laparoscopic anterior partial fundoplication (according to Watson) was found to be clearly inferior. Regarding side effects it was not possible to reveal any differences in obstructive complaints between the two partial fundoplications, but interestingly enough significantly more patients reported an ability to vomit after the anterior fundoplication. This observation probably reflects the efficacy of the respective repair. Why should an anterior partial fundoplication function differently from a posterior one? The extent of the distal esophageal body that is encircled by the actual wrap varies somewhat between the respective procedures. The posterior fundoplication elevates the abdominal portion of the esophagus from its native bed in the hiatus and by necessity angulated the gastroesophageal junction. The significance of this has to be better clarified but it may have the potential to cause some esophageal outflow obstruction. Also, it is totally unclear whether it contributes to a better mechanical barrier to prevent gastroesophageal reflux. The anterior partial fundoplication performed and recently validated by Watson et al. [98] from Australia, differs somewhat from that originally described in 1991 [85]. The message, however, is clear: if a partial fundoplication is chosen, it has to be a complete anterior $180^{\circ}$ wrap, but more studies are required to give firm guidance to the clinicians.

\section{Concluding Remarks}

Surgery should always be looked upon as complementary to medical therapy in the long-term management of patients with chronic GERD. GERD represents an increasing health problem among adults in the Western world. Available medical therapies are effective and adequate for the control of disease manifestations in the great majority of GERD patients. For patients who have a suboptimal disease control under medical therapy and in those who for various reasons want to discuss an alternative to medical long-term therapy, the following message can be transmitted. ARS is a well-documented effective long-term therapeutic alternative to control GERD. The outcome after surgery is dependent on the experience and quality of the surgeon. These operations are safe but mortality can never attain a zero level and the morbidity has to be realized. ARS has to be centralized within each country.

With the aim of optimizing the outcome of ARS, the surgeon has to perform and master a delicate act of balance in the choice between various fundoplication procedures. On one hand, we have the total fundoplication with its proven efficacy regarding reflux control but with it associated mechanical side effects leading to symptoms related to the relative obstruction in the gastroesophageal junction and the inability to vent air from the stomach and the sequel that follow. The posterior partial fundoplication has obvious advantages with fewer postfundoplication complaints without compromising the level of reflux control and can therefore often be recommended. Some studies present very promising results following anterior partial fundoplications, but confirmative studies are warranted. The spectrum of postfundoplication symptoms can be minimized provided that the surgeon fully comprehends the mechanism of action of these procedures and adheres to technical perfectionism.

\section{References}

- 1 Laine L, Ahnen D, McClain C, Solcia E, Walsh JH: Review article: potential gastrointestinal effects of long-term acid suppression with proton pump inhibitors. Aliment Pharmacol Ther 2000;14:651-668.

2 Klinkenberg-Knol EC, Festen HP, Jansen JB, Lamers CB, Nelis F, Snel P, et al: Long-term treatment with omeprazole for refractory reflux esophagitis: efficacy and safety. Ann Intern Med 1994;121:161-167.

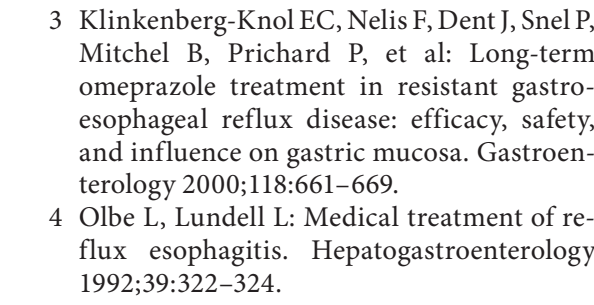

5 Vigneri S, Termini R, Leandro G, et al: A comparison of maintenance therapies for reflux esophagitis. N Engl J Med 1995;333: 1106-1110.

-6 Carlsson R, Galmiche JP, Dent J, Lundell L, Frison L: Prognostic factors influencing relapse of oesophagitis during maintenance therapy with antisecretory drugs: a metaanalysis of long-term omeprazole trials. Aliment Pharmacol Ther 1997;11:437-482. 
7 Dent J, Brun J, Fenwick AM, Fennerty MB, Janssens J, Kahrilas PJ, Lauritsen K, Reynolds JC, Shaw M, Talley NJ: An evidencebased appraisal of reflux disease management - the Genval Workshop Report. Gut 1999;44(suppl 2):1-16.

8 Edwards SJ, Lind T, Lundell L: Systematic review of proton pump inhibitors for the maintenance of healed reflux oesophagitis. J Outcomes Res 2002;6:1-14.

-9 Armstrong D, Talley NJ, Lauritsen K, Moum B, Lind T, Tunturi-Hihnala H, Venables T, Green J, Bigard MA, Mossner J, Junghard O: The role of acid suppression in patients with endoscopy-negative reflux disease: the effect of treatment with esomeprazole or omeprazole. Aliment Pharmacol Ther 2004;20:413421.

10 DeVault KR, Johansson JF, Johnson DA, Liu S, Sostek MB: Maintenance of healed erosive esophagitis: a randomized 6-month comparison of esomeprazole $20 \mathrm{mg}$ with lasoprazole $15 \mathrm{mg}$. Clin Gastroenterol Hepatol 2006; 4:852-859.

11 Chiba N: Proton pump inhibitors in acute healing and maintenance of erosive or worse esophagitis: a systematic overview. Can J Gastroenterol 1997;11(suppl B): 66-73.

-12 DeVault KR, Castell DO: Updated guidelines for the diagnosis and treatment of gastroesophageal reflux disease. Am J Gastroenterol 2005; 100:190-200.

$\checkmark 13$ Dean BB, Gano A Jr, Knight K, et al: Effectiveness of proton pump inhibitors in nonerosive reflux disease. Clin Gastroenterol Hepatol 2004;2:656-664.

14 Behar J, Sheahan DG, Biancani P: Medical and surgical management of reflux oesophagitis, a 38-month report on a prospective clinical trial. N Engl J Med 1975;293:263268.

- 15 Ortiz A, Martinez de Haro LF, Parrilla P, Morales G, Molina J, Bermejo J, Liron R, Aguilar J: Conservative treatment versus antireflux surgery in Barrett's esophagus: longterm results of a prospective study. Br J Surg 1996;83:274-278.

16 Spechler SJ: Comparison of medical and surgical therapy for complicated gastroesophageal reflux disease in veterans. N Engl J Med 1992;326:786-792.

17 Spechler SJ, Lee E, Ahnen D, et al: Long-term outcome of medical and surgical therapies for gastroesophageal reflux disease. Followup of a randomized controlled trial. JAMA 2001;285:2331-2338.

18 Lundell L, Miettinen P, Myrwold ME, et al: Continued (5-year) follow-up of a randomised clinical study comparing antireflux surgery and omeprazole in gastroesophageal reflux disease. J Am Coll Surg 2001;192:172179.

19 Lundell L, Miettinen P, Myrvold ME, Wallin L, et al: Medical or surgical treatment for reflux esophagitis; 7-year follow-up of a randomised clinical trial. Br J Surg 2007, in press.
20 Mahon D, Rhodes M, Decadt B, Hindmarsch A, Lowndes R, Beckingham I, Koo B, Newcombe RG: Randomized clinical trial of laparoscopic Nissen fundoplication compared with proton-pump inhibitors for treatment of chronic gastro-oesophageal reflux. Br J Surg 2005;92:695-699.

21 Mehta S, Bennett J, Mahon D, Rhodes M: Prospective trial of laparoscopic Nissen fundoplication versus proton pump inhibitor therapy for gastroesophageal reflux disease: 7-year follow-up. J Gastrointest Surg 2006; 10:1312-1317.

22 Blomqvist A, Lönroth H, Dalenbäck J, Ruth M, Wiklund I, Lundell L: Quality-of-life assessment after laparoscopic and open fundoplications: results of a prospective, clinical study. Scand J Gastroenterol 1996;31:10521058 .

23 Dimenas E, Glise H, Hallerback B, Hernqvist $\mathrm{H}$, Svedlund J, Wiklund I: Quality of life in patients with upper gastrointestinal symptoms: An improved evaluation of treatment regimens? Scand J Gastroenterol 1993;28: 681-687.

24 Velanovich V, Vallance SR, Gusz JR, Tapia FV, Harkabus MA: Quality-of-life scale for gastroesophageal reflux disease. J Am Coll Surg 1996;183:217-224.

25 Kamolz T, Pointner R, Velanovich V: The impact of gastroesophageal reflux disease on quality of life. Surg Endosc 2003;17:11931199.

26 Kamolz T, Granderath FA, Pointner R: The outcome of laparoscopic antireflux surgery in relation to patients' subjective degree of compliance with former antireflux medication. Surg Laparosc Endosc Percutan Tech 2003;13:155-160.

27 Kamolz T, Pointner R: Expectations of patients with gastroesophageal reflux disease for the outcome of laparoscopic antireflux surgery. Surg Laparosc Endosc Percutan Tech 2002;12:389-392.

28 Kamolz T, Granderath FA, Pointner R: Does major depression in patients with gastroesophageal reflux disease affect the outcome of laparoscopic antireflux surgery? Surg Endosc 2003;17:55-60.

29 Bammer T, Freeman M, Shahriari A, Hinder RA, DeVault KR, Achem SR: Outcome of laparoscopic antireflux surgery in patients with nonerosive reflux disease. J Gastrointest Surg 2002;6:730-737.

30 Winslow ER, Frisella MM, Nathaniel RN, Soper J, Clouse RE, Klingensmith ME: Patients with upright reflux have less favourable postoperative outcomes after laparoscopic antireflux surgery than those with supine reflux. J Gastrointest Surg 2002;6: 819-830.

-31 So JBY, Zeitels SM, Rattner DW: Outcomes of atypical symptoms attributed to gastroesophageal reflux treated by laparoscopic fundoplication. Surgery 1998;124:28-32.
32 Kamolz T, Granderath FA, Schweiger UM, Pointner R: Laparoscopic Nissen fundoplication in patients with nonerosive reflux disease. Long-term quality-of-life assessment and surgical outcome. Surg Endosc 2005; 19 : 494-500.

-33 Sifrim D, Holloway R, Silny J, Tack J, Lerut A, Janssens J Composition of the postprandial refluxate in patients with gastroesophageal reflux disease. Am J Gastroenterol 2001; 96:647-655.

34 DeMeester TR, Bonavina L, Lascone C, et al: Chronic respiratory symptoms and occult gastroesophageal reflux: a prospective clinical trial and results of surgical therapy. Ann Surg 1990;211:337-345.

35 Ruth M, Bake B, Sandberg N, et al: Pulmonary function in gastroesophageal reflux disease. Effects of reflux controlled by fundoplication. Dis Esophagus 1994;7:268-275.

36 Vollan G, Stangeland L, Søreide JA, Janssen CW, Svanes K: Long-term results after Nissen fundoplication and Belsey Mark IV operation in patients with reflux oesophagitis and stricture. Eur J Surg 1992;158:357-360.

37 Bonavina L, Fontebasso V, Bardini R, Baessato M, Peracchia A: Surgical treatment of reflux stricture of the oesophagus. Br J Surg 1993;80:317-320.

38 Spivak H, Farrell TM, Trus TL, Branum GD, Waring JP, Hunter J: Laparoscopic fundoplication for dysphagia and peptic esophageal stricture. J Gastrointest Surg 1998;2:555560 .

39 Little AG, Naunheim KS, Ferguson MK, Skinner DB: Surgical management of esophageal stricture. Ann Thorac Surg 1988;45: 144-147.

40 Zaninotto G, DeMeester TR, Bremner CG, et al: Esophageal function in patients with reflux-induced stricture and its relevance to surgical treatment. Ann Thorac Surg 1989; 47:362-370

41 Mercer CD, Hill LD: Surgical management of peptic esophageal stricture. J Thorac Cardiovasc Surg 1986;91:3471-3478.

42 Pinotto HW, Pollara WM, Zilberstein B, Cecconello I, Raia A: Stenosing reflux esophagitis. Indications and results of conservative treatment. AMB Rev Assoc Med Bras 1982;28:107-110.

43 Pearson FG, Henderson RD: Long-term follow-up of peptic strictures managed by dilatation modified Collis gastroplasty, and Belsey hiatus hernia repair. Surgery 1976;80: 396-404.

44 Braghetto I, Csendes A, Burdiles P, et al: antireflux surgery, highly selective vagotomy and duodenal switch procedure: postoperative evolution in patients with complicated and non-complicated Barrett's esophagus. Dis Esophagus 2000;13:12-17. 
45 Csendes A, Braghetto I, Burdiles P, Puente G, Korn O, Diasz JC, Maluenda F: Long-term results of classic antireflux surgery in $152 \mathrm{pa}-$ tients with Barrett's esophagus: clinical, radiologic, endoscopic, manometric, and acid reflux test analysis before and late after operation. Surgery 1998;123:545-557.

-46 Csendes A, Burdiles P, Korn O, Braghetto I, Huertas C, Maluenda F, Diaz J, Rojas J: Late results of a randomised clinical trial comparing total fundoplication versus calibration of the cardia with posterior gastropexy. Br J Surg 2000;87:289-297.

- 47 Hofstetter WL, Peters JH, DeMeester TR, et al: Long-term outcome of anti-reflux surgery in patients with Barrett's esophagus. Ann Surg 2001;234:532-538.

-48 Farrell TM, Smith CD, Metreveli RE, et al: Fundoplication provides effective and durable symptom relief in patients with Barrett's esophagus. Am J Surg 1999;178:18-21.

-49 O’Boyle CJ, Watson DI, DeBeaux AC, Jamieson GG: Preoperative prediction of longterm outcome following laparoscopic fundoplication. Aust NZ J Surg 2002;72:471-475.

- 50 Brand DL, Yenisaker JT, Gelfand M, et al: Regression of columnar esophageal (Barrett's) epithelium after anti-reflux surgery. N Engl J Med 1980;302:844-848.

-51 Skinner DB, Walther BC, Riddell RH, et al: Barrett's esophagus: comparison of benign and malignant cases. Ann Surg 1983;198: 554-566.

- 52 Starnes VA, Adkins RB, Ballinger JF, et al: Barrett's esophagus. A surgical entity. Arch Surg 1984;119:563-567.

-53 DeMeester TR, Attwood SEA, Smyrk TC, et al: Surgical therapy in Barrett's esophagus. Ann Surg 1990;212:528-542.

- 54 Williamson WA, Ellis FHE, Gibb SP, Shahian DM, Aretz T: Effect of antireflux operation on Barrett's mucosa. Ann Thorac Surg 1990;49:537-542

55 McEntee GP Stuart RC, Byrne PS, et al: An evaluation of surgical and medical treatment of Barrett's esophagus. Gullet 1991;1:169172.

56 McCallum RW, Polepalle S, Dawenport K, et al: Role of anti-reflux surgery against dysplasia in Barrett's esophagus. Gastroenterology 1991;100:A121.

- 57 Attwood SEA, Barlow AP, Norris TL, Watson A: Barrett's esophagus: effect of antireflux surgery on symptom control and development of complications. Br J Surg 1992;79: 1050-1053.

- 58 Sagar PM, Ackroyd R, Hosie KB, Pattersson JE, Stoddard CJ, Kingsnorth AN: Regression and progression of Barrett's esophagus after antireflux surgery. Br J Surg 1995;82:806810.

-59 McDonald ML, Trastek VF, Allen M, Deschamps C, Pairolero PC: Barrett's esophagus: Does an antireflux procedure reduce the need of endoscopic surveillance? J Thorac Cardiovasc Surg 1996;111:1135-1140.
60 DeMeester SR, Campos GMR, DeMeester TR, et al: The impact of anti-reflux surgery on intestinal metaplasia of the cardia. J Gastrointest Surg 1998;228:547-556.

61 Low DE, Levine DS, Dail DH, Kozarek RA: Histological and anatomic changes in Barrett's esophagus after antireflux surgery. Am J Gastroenterol 1999;94:80-85.

62 Patti MG, Arcentino M, Feo CV, et al: Barrett's esophagus. A surgical disease. J Gastrointest Surg 1999;3:397-404.

63 Parrilla P, Martínez de Haro LF, Ortiz A Munitiz V, Serrano A, Torres G: Barrett's esophagus without esophageal stricture does not increase the rate of failure of Nissen fundoplication. Ann Surg 2003;237:488493.

64 O’Riordan JM, Byrne PJ, Ravi N, Keeling PWN, Reynolds JV: Long-term clinical and pathologic response of Barrett's esophagus after antireflux surgery. Am J Surg 2004;188: 27-33.

65 Catarci M, Gentileschi P, Papi C, et al: Evidence-based appraisal of antireflux fundoplication. Ann Surg 2004;239:325-337.

66 Booth MI, Jones L, Stratford J, Dehn TCB: Results of laparoscopic Nissen fundoplication at 2-8 years after surgery. Br J Surg 2002 89:476-481.

67 Granderath FA, Kamolz T, Schweiger UM, Pointner R: Quality of life, surgical outcome and patient satisfaction three years after laparoscopic Nissen fundoplication. World J Surg 2002;26:1234-1238.

68 Watson DI, Baigrie RJ, Jamieson GG: A learning curve for laparoscopic fundoplication. Definable, avoidable or a waste of time? Ann Surg 1996;224:198-203.

69 Sandbu R, Khamis H, Gustavsson S, Haglund U: Long-term results of antireflux surgery indicate the need for a randomised clinical trial. Br J Surg 2002;89:225-230.

70 Watson DI, Jamieson GG: Antireflux surgery in the laparoscopic era. Br J Surg 1998; 85:1173-1184.

71 Perdikis G, Hinder RA, Lund RJ, Raiser F Katada N: Laparoscopic Nissen fundoplication: Where do we stand? Surg Laparosc Endosc 1997;7:17-21.

-72 Anvari M, Allen C, Borm A: Laparoscopic Nissen fundoplication is a satisfactory alternative to long-term omeprazole therapy. $\mathrm{Br} \mathrm{J}$ Surg 1995;82:938-942.

73 Watson DI, Jamieson GG, Baigrie RJ, et al: Laparoscopic surgery for gastro-oesophageal reflux: beyond the learning curve. $\mathrm{Br}$ Surg 1996;223:1284-1287.

74 Laine S, Rantala A, Gullichsen R, Ovaska J: Laparoscopic vs. conventional Nissen fundoplication. A prospective randomized study. Surg Endoscopic 1997;11:441-444.

75 Nilsson G, Larsson S, Johnsson F: Randomized clinical trial of laparoscopic versus open fundoplication: blind evaluation of recovery and discharge period. Br J Surg 2000;87:873878 .
76 Nissen R: Eine einfache Operation zur Beeinflussung der Reflux Oesophagitis. Schweiz Med Wochenschr 1956;86:590.

77 Peracchia A, Bancewicz J, Bonavina L, et al: Fundoplication is an effective treatment for gastro-oesophageal reflux disease. Gastroenterol Int 1995;8:1-7.

-78 Negre JB, Markkula HT, Keyriläinen O, Matikainen M: Nissen fundoplication. Results at 10-year follow-up. Am J Surg 1983; 146:635-638.

79 Garstin WI, Johnston GW, Kennedy TL, Spencer ES: Nissen fundoplication: the unhappy 15\%. J R Coll Surg Edinb 1986;31:207209.

80 DeMeester TR, Bonavina L, Albertucci M: Nissen fundoplication for gastroesophageal reflux disease. Evaluation of primary repair in 100 consecutive patients. Ann Surg 1986; 204:9-20.

81 Luostarinen M, Isolauri J, Laitinen J, Koskinen $\mathrm{M}$, Keyriläinen $\mathrm{O}$, Markkula $\mathrm{H}$, Lehtinen E, Uusitalo A: Fate of Nissen fundoplication after 20 years. A clinical, endoscopical and functional analysis. Gut 1993;34:10151020

82 Lundell L, Abrahamsson H, Ruth M, Rydberg L, Lönroth H, Olbe L: Long-term results of a prospective randomised comparison of total fundic wrap (Nissen-Rossetti) or semifundoplication (Toupét) for gastroesophageal reflux. Br J Surg 1996;83:830-835.

83 Toupét A: Technique d'œsophago-gastroplastie avec phrénogastropexie appliquée dans la crure radicale des hernies hiatales et comme complément de l'opération de Heller dans les cardiospasmes. Mem Acad Chir 1963:89:394-398

84 Walker SJ, Holt S, Sanderson CJ, Stoddard CJ: Comparison of Nissen total and Lind partial transabdominal fundoplication in the treatment of gastro-oesophageal reflux. Br J Surg 1992;79:410-414.

85 Watson A, Jenkinson LR, Ball CS, Barlow AP, Norris TL: A more physiological alternative to total fundoplication for the surgical correction of resistant gastro-oesophageal reflux. Br J Surg 1991;78:1088-1094.

-86 Segol P, Hay JM Pottier D: Surgical treatment of gastroesophageal reflux: which operation to choose: Nissen, Toupét or Lotart-Jacob? Gastroenterol Clin Biol 1989;13:873-879.

87 Thor KBA, Silander T: A long-term randomized prospective trial of the Nissen procedure versus a modified Toupét technique. Ann Surg 1989:210; 719-724.

88 Lundell L, Abrahamsson H, Ruth M, Sandberg N, Olbe L: Lower esophageal sphincter characteristics and esophageal acid exposure following partial or $360^{\circ}$ fundoplication: results of a prospective, randomised, clinical study. World J Surg 1991;15:115. 
89 Lundell L, Abrahamsson H, Ruth M, Rydberg L, Lönroth H, Olbe L: Long-term results of a prospective randomised comparison of total fundic wrap (Nissen-Rossetti) or semifundoplication (Toupét) for gastro-esophageal reflux. Br J Surg 1996;83:830-835.

-90 Rydberg L, Ruth M, Abrahamsson H, Lundell L: Tailoring antireflux surgery: a randomised clinical trial. World J Surg 1999;23: 612-618.

-91 Walker SJ, Holt S, Sanderson CJ, et al: Comparison of Nissen total and Lind partial transabdominal fundoplication in the treatment of gastro-oesophageal reflux. Br J Surg 1992;79:410-414

$\checkmark 92$ Csendes A, Burdiles P, Korn O, et al: Late results of a randomised clinical trial comparing total fundoplication versus calibration of the cardia with posterior gastropexi. $\mathrm{Br} \mathrm{J}$ Surg 2000;87:289-297.

$\checkmark 93$ Fibbe C, Layer P, Keller J, et al: Esophageal motility in reflux disease before and after fundoplication: a prospective, randomized, clinical and manometric study. Gastroenterology 2001;212:5-14.
94 Zorning C, Strate U, Fibbe C, et al: Nissen vs. Toupét laparoscopic fundoplication. A prospective randomized study of 200 patients with and without preoperative esophageal motility disorders. Surg Endosc 2002;16: 758-766.

95 Hagedorn C, Lönroth H, Rydberg L, Ruth M, Lundell L: Long-term efficacy of total (Nissen-Rossetti) and posterior partial (Toupét) fundoplication: result of a randomized clinical trial. J Gastroint Surg 2002;4:540-545.

96 Engström C, Blomqvist A, Dalenbäck J, Lönroth $\mathrm{H}$, Ruth M, Lundell L: Mechanical consequences of short gastric vessel division at the time of laparoscopic total fundoplication. J Gastroint Surg 2004;4:442-447.

97 Horvath KD, Jobe BA, Herron DM, Swanstrom LL: Laparoscopic Toupét fundoplications is an inadequate procedure for patients with severe reflux disease. J Gastrointest Surg 1999;583-591.

98 Watson DI, Jamieson GG, Pike GK, et al Prospective randomized double-blind trial between laparoscopic Nissen fundoplication and anterior partial fundoplication. $\mathrm{Br} \mathrm{J}$ Surg 1999;86:123-130.
\$9 Lindboom MA, Ringers J, Straathof JW, van Rijn PJ, et al: Effect of laparoscopic partial fundoplication on reflux mechanisms. Am J Gastroenterol 2003;98:29-34.

100 O’Reilly MJ, Mullins SG, Saye WB, Pinto SE, Falkner PT: Laparoscopic posterior partial fundoplication: analysis of 100 consecutive cases. J Laparoendosc Surg 1996;6: 141-150.

101 Cambell KL, Munro A: Efficacy and incidence of post-fundoplication symptoms at a median of 5 years following open Watson fundoplication. Br J Surg 1998;85(suppl $1): 8$.

102 Watson DI, Liu J, Devitt PG, Game PA, Jamieson GG: Outcome of laparoscopic anterior $180^{\circ}$ partial fundoplication for gastroesophageal reflux disease. J Gastrointest Surg 2000;4:486-492.

103 Hagedorn C, Jönsson C, Lönroth H, et al: Efficacy of an anterior as compared with a posterior laparoscopic partial fundoplication. Result of a randomized, controlled clinical trial. Ann Surg 2003;238:189-196. 